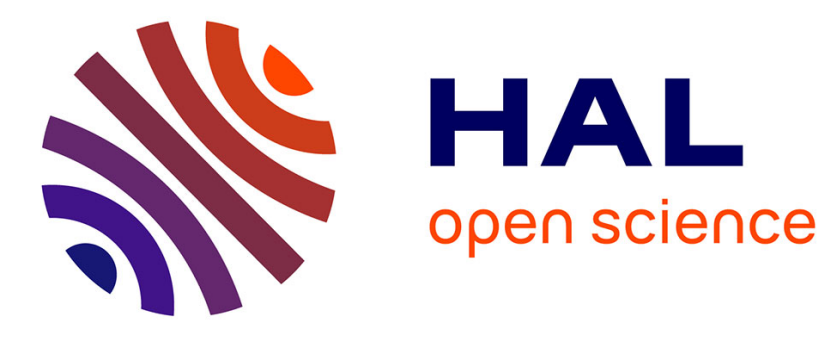

\title{
A Framework to Support Industry 4.0: Chemical Company Case Study
}

\author{
Daniel Cortés Serrano, Dante Chavarría-Barrientos, Arturo Ortega, Belén \\ Falcón, Leopoldo Mitre, Rodrigo Correa, Jaime Moreno, Rafael Funes, Arturo \\ Molina Gutiérrez
}

\section{To cite this version:}

Daniel Cortés Serrano, Dante Chavarría-Barrientos, Arturo Ortega, Belén Falcón, Leopoldo Mitre, et al. A Framework to Support Industry 4.0: Chemical Company Case Study. 19th Working Conference on Virtual Enterprises (PRO-VE), Sep 2018, Cardiff, United Kingdom. pp.387-395, 10.1007/978-3319-99127-6_33. hal-02191185

\section{HAL Id: hal-02191185 \\ https://hal.inria.fr/hal-02191185}

Submitted on 24 Jul 2019

HAL is a multi-disciplinary open access archive for the deposit and dissemination of scientific research documents, whether they are published or not. The documents may come from teaching and research institutions in France or abroad, or from public or private research centers.
L'archive ouverte pluridisciplinaire HAL, est destinée au dépôt et à la diffusion de documents scientifiques de niveau recherche, publiés ou non, émanant des établissements d'enseignement et de recherche français ou étrangers, des laboratoires publics ou privés.

\section{(c)(1)}

Distributed under a Creative Commons Attribution| 4.0 International License 


\title{
A Framework to Support Industry 4.0: Chemical Company Case Study
}

\author{
Daniel Cortés Serrano ${ }^{1}$, Dante Chavarría-Barrientos ${ }^{1}$, Arturo Ortega ${ }^{2}$, Belén \\ Falcón $^{2}$, Leopoldo Mitre ${ }^{2}$, Rodrigo Correa ${ }^{2}$, Jaime Moreno ${ }^{2}$, Rafael Funes ${ }^{2}$, Arturo \\ Molina Gutiérrez ${ }^{1}$ \\ ${ }^{1}$ Product Innovation Research Group, Tecnologico de Monterrey, School of Engineering \\ and Science, Mexico \\ $\{\mathrm{a} 01655708$, dante.chavarria, armolina $\} @$ itesm.mx \\ ${ }^{2}$ LOVIS, Mexico \\ \{arturo.ortega, belen.falcon, leopoldo.mitre, rodrigo.correa, jaime.moreno, \\ rafael.funes\}@lovis.email
}

\begin{abstract}
The concept of Industry 4.0 corresponds to a new way of organizing the production of goods, taking smarter decisions based on environmental variables and optimizing available resources. However, there is still a journey to carry out the implementation of this concept with current technologies. To make this transformation of the industry, it is necessary to characterize the Industry 4.0 concept, adopt a strategic thinking, and acquire skills, aptitudes, and attitudes. Enterprise reference models can help in orchestrating the change, however, the relationship between existing reference models and Industry 4.0 needs further clarification. Thus, this paper proposes a framework that links a reference model with the Industry 4.0 concept. Furthermore, a tool for the instantiation of the framework is proposed to provide practical approach. And the results of implementing the proposed framework are presented in a case study.
\end{abstract}

Keywords: Industry 4.0, Cyber-Physical Systems, Industrial Internet of Things, Enterprise Operating System, Cognitive Systems.

\section{Introduction}

Today, enterprises need to be designed according to customer requirements, optimize available resources, become agile and respond to market changes in intelligent manners [1]. Enterprises are immersed in their context and operation. Monitoring continues changes over environmental variables are expected to adopt new strategies. To make smarter decisions it is necessary to create Collaborative Networks of Cognitive Systems which could exploit new technologies such as Big Data, Industrial Internet of Things, Advanced Robotics, Artificial Intelligence, Hyperconnectivity, Cloud Computing, Cybersecurity, Additive Manufacturing and Cyber-Physical Systems [2]. With the application of this technologies, an enhance their reactive and proactive capabilities are expected [3][4]. Sensing technology is now a reality and 
adaption of these sensors to obtain real-time data is proving a competitive advantage to enable context and knowledge-based decision making [5].

Virtues of Industry 4.0 were planned to respond a need in the production of goods [6], the concept has been expanded to planning, supply chain logistics, product development, and services, though. Company's value chain facilitates the flow of information from the physical world to business decisions in real time with these technologies. Within Industry 4.0 vision, each company need to identify every part of the enterprise which could contribute to data system taking advantage of different information extracted by different sensors measuring either environment or own resources [7] and decisions would be based on current information, considering the total behavior of the enterprise. Thus, transitioning from conventional factories into Smart Factories and creating a Collaborative Network (CN).

Even CNs are part of the transition towards Industry 4.0 enterprises, there is still missing references on how to accomplish it. This paper aims at that purpose introducing a framework and a successful case study from a Chemical Sector Company where Enterprise Operating System designed is implemented and virtues of Industry 4.0 have to yield them. The Paper organizes as follows, Section 2 describes the relationship between CNs and Industry 4.0. Then, Section 3 describes framework and EOS as a solution and methodological approach towards Industry 4.0. Then, Section 4 presents an applied case study. Finally, Section 5 provides conclusions and future work.

\section{Industry 4.0, Collaborative Networks and Reference Models}

Industry 4.0 proposes the use of technology and connections to generate a system capable of obtaining data from the environment to make smart decisions. According to [8] principles that lead to Industry 4.0 are 1) interconnection: ability of machinery to communicate with people through networking, 2) information transparency: capability of information systems and CPS to create virtual copies of the physical world into digital models aided by sensors, 3 ) decentralized decisions: enable cyber systems to come up with decisions to complete intended goals and 4) technical assistance: ability of the system to support human decisions through different indicators.

On the other hand, Smart Factories are environments where hardware and software interact throughout sensors and actuators interconnected in real time and enable manufacturing relevant information anytime anywhere.

Therefore, Industry 4.0 would not be possible if connection among different areas is omitted in facilities design, that is, if there is no communication and information shared, there would not be possible to generate Smart Factories [9], [10] where humans are decision makers instead of operators. Cyber-Physical Systems (CPS) integrate computing and communication capabilities enabling networking from hardware and software with human beings [2]. In fact, CNs are enablers for Industry 4.0, where every technology acquired must contribute data generation for better decisions [3]. 
Nonetheless, even there are technological advantages that enable Industry 4.0, there are also factors that have limited the progress of the fourth industrial revolution, among them, uncertainty is a recurring theme that has reduced the inclusion of various technological systems. Thus, the main obstacles to become part of Industry 4.0 are [11],[12]:

- The lack of digital culture and adequate training.

- Resistance to change.

- The absence of a clear vision of digital operations and the leadership of senior management.

- A confused knowledge of the economic benefits of investing in digital technologies.

- Reliability of digital security.

Reference models aim of being reused for different but similar application scenarios [13], enabling minimize obstacles, recognition of capabilities required and clarifying new opportunity areas for revenue increase. A structured vision of technology when instantiating reference models allows identifying information flow and risks involved. An instantiation is done to generate the proposed framework.

\section{Proposed Framework}

CNs are enablers of the fourth industrial revolution because all principles of Industry 4.0 are related. On the other hand, reference models tackle the main obstacles to adopt Industry 4.0. In recent years, Sensing, Smart and Sustainable System $\left(S^{3}\right)$ [14] has been a conceptualized model of how decision must be taken in enterprises, products must be developed, cities must be planned, and the world must be conceived taking advantage of available technological resources. In that sense, the fourth industrial revolution could be achieved by Smart Factories applying $\mathrm{S}^{3}$ principles aided by CNs (View Figure 1).

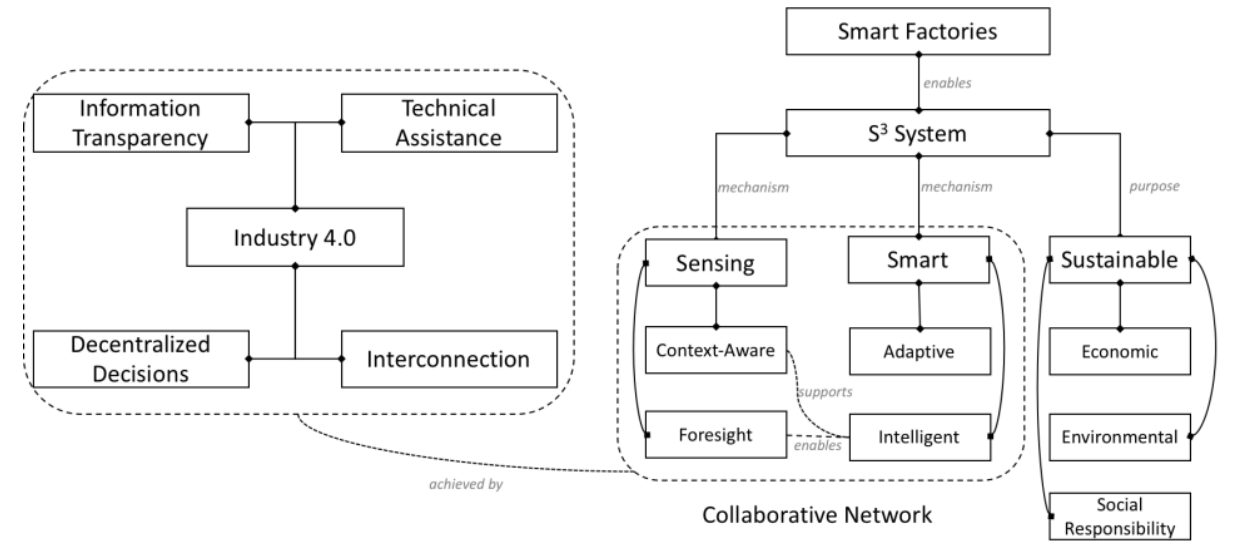

Figure 1. Collaborative Network conceptual model. 
Sensing and Smart principles from $\mathrm{S}^{3}$ Systems are correlated with Interconnection from Industry 4.0, that enables a Collaborative Network where machines from Smart Factories are capable of providing real-time internal or environmental information in order to make decisions making it more automated.

Not only $\mathrm{S}^{3}$ system has offered a start point for Smart Factories, but also, it has been conceived from five viewpoints defining a reference model. S3-RM also has been instantiated, activities and tools are provided for its application in different contexts in [15].

Thus, Smart Factories developed in the context of Industry 4.0 require to monitor functions, Yusuf has proposed five components to measure in order to accomplish that purpose [16]:

- Enterprise Resource Management (ERM): obtains the status of resources in a dynamic way.

- Enterprise Process Management (EPM): executes and coordinates business processes defined by internal processes.

- Enterprise Information Management (EIM): coordinates, protects and supports the exchange of information between the resources connected to the system.

- Presentation Management (EP): consists of a series of services that provide information in real time on commercial resources feed the system through the exchange of information, which allows better control.

- Interoperability Management (IM): is a series of services that provide the mapping of heterogeneous resources to operate them.

Enterprise Operating System (EOS) concept emerged as a solution to monitor ERM, EPM, EIM, EP, and IM, it was put into practice in the last decade [17], however, the objectives and concepts that it seeks are older. The concept appeared at the end of the 1980s, in the form of an integrated infrastructure within CIMOSA [18] architecture. $\mathrm{S}^{3}-\mathrm{RM}$ has been used to define EOS solution according to five viewpoints proposed [17] as shown in Figure 2.

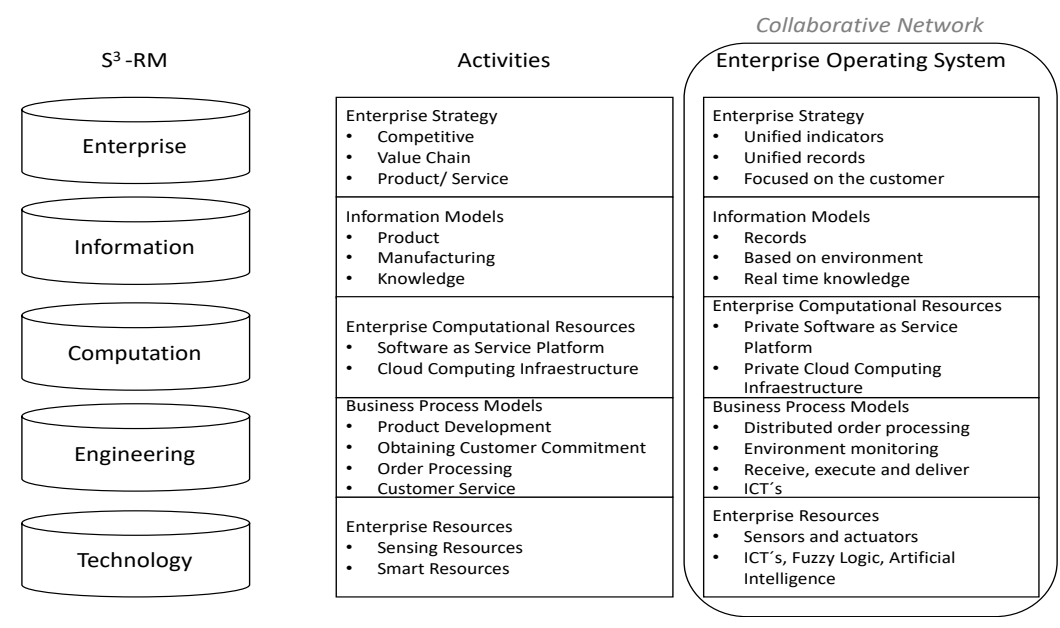

Figure 2 Enterprise Operating System solution 
All activities presented for EOS solution are also a Collaborative Network, due to the fact that every viewpoint is satisfied using shared resources in a system. Therefore, EOS solution also conceived as a Collaborative Network is able to lead into Smart Factories (an S3-System) through $\mathrm{S}^{3}$-RM which leads into Industry 4.0. All five viewpoints aim at covering four pillars of Industry 4.0. Gathering information from different areas promoting decentralized decisions is achieved by enterprise strategy and business process model. Virtualizing reality to accomplish information transparency and interconnection is achieved by information, computation and technology resources. Thus, the proposed framework is presented in Figure 3.

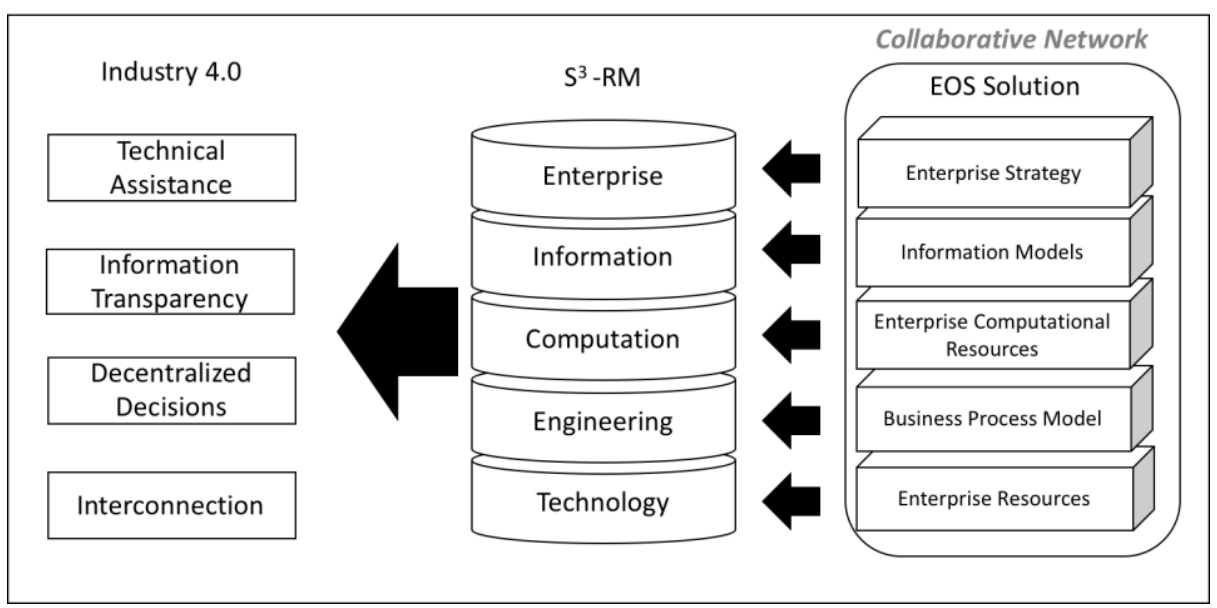

Figure 3 Reference Framework, EOS Solution as Industry 4.0 catalyst

According to Figure 3, all information collected in real time by EOS aims to establish a long-term vision for the enterprise, search for dynamic solutions, unify records, optimize value creation focused on customers and decision making of firms. EOS solution is then a Collaborative Network between human beings and CPS, but above all else, between its environment which could also create CNs between enterprises, providers, clients and different entities.

\section{Case Study}

LOVIS enterprise (https://www.lovis.com/en) has developed a complete EOS solution based on CNs between areas of the enterprise. One of his clients, a Chemical Sector Company which belongs to the automotive sector, had an ERP developed to its measure, however, the growth of the company and its diversification have caused that it is no longer a viable option without a considerable investment. The company has grown larger over the years and the complexity of its activities has adapted more efficiently to EOS solution by LOVIS. 
The adoption of this system has allowed a $\mathrm{CN}$ inside the company which allows better control of resources, real-time knowledge of the system and a more detailed interaction of the areas that make up the company. Even reluctant to change from the company due to the large investment in ERP solution, EOS benefits were presented causing the company to adopt a newer solution as shown in Figure 4. Five Viewpoints were considered for a company to transition into EOS using $\mathrm{S}^{3}$-RM.

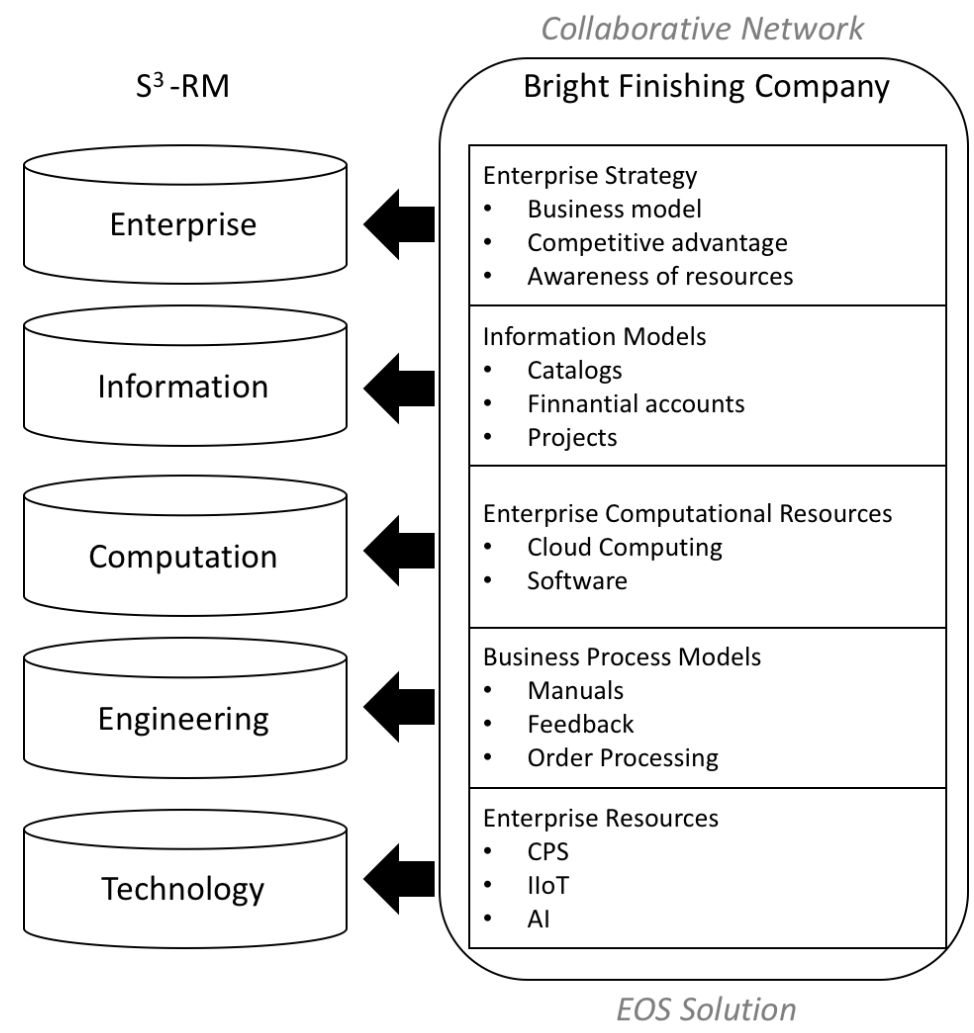

Figure 4 Reference Framework, Instantiated for Bright Finishing company

Enterprise Viewpoint, aided by digital operation and management lead the company to Flexibility. The company started its activities and took control in a traditional way until the acquisition of a customized ERP system, however, the complexity of its activities and processes led them to look for other alternatives that would allow flexibility in the production lines. EOS solution (View Figure 4) allowed to face these difficulties, flexible structure allowed the incorporation of different product lines and the materials used in each stage of the process.

Technology Viewpoint allowed the company to acquire Reconfigurability. Due to the type of system that was available, the areas were seen as modules, this changed with the implementation of newer system, making them more flexible and reconfigurable, since all the information that is processed communicates with the rest of areas and allows to identify vulnerable points in the production line, once identified 
the areas of opportunity, it is possible to reconfigure the system to optimize the lines, but above all adapt it to the growth of the plant. Therefore, introducing cloud services and higher cyber-security, with business activities carried out in Mexico and the United States it was necessary that the information handled is available, be able to adapt to changes regarding business policies and monitor activities anywhere.

Engineering viewpoint was covered making use of Digitalization. The manufacturing company of the automotive sector performed the processes in a traditional way, and although computer records were kept all phases of the process were optimized and digitized with the newer acquisition, economic benefits are presented due to resource administration. Today, the company relies on the IIoT to track resources, as well as the reprocessing of parts, which existed and a paper control was carried out. After the implementation, transactions have been made online using Cloud Computing, which allows verifying at all times the pieces that make up the process and their status along the value chain. The level of follow-up of the raw material had been a particularly complex subject, due to the flexibility that this system allows, it has been solved in its entirety and allows to carry out other activities such as accounting, financial and organizational strategies for future productions.

Information and computation viewpoint allowed Smartisation in the company. The level of smartness of the company has been gradually increasing, currently, the sensors that allow monitoring the production process are integrated into the daily activities of operators and the same production line, training is one of the most important programs for the company nowadays. In order to carry out the monitoring in real time, sensors and verifiers have been implemented in all the stages in order to know the current status and what has been done. Thus, when it is necessary to know the current situation of the company, it is enough to consult the EOS register and it is possible to take actions that improve the current situation. Knowing what happens in real time within the company has allowed delegating, detailed scheduling of deliveries, disposition of resources and cash flows. Thus, the integration of the EOS solution solves the basic management activities for the organization.

Adopted technologies were mostly IIoT, CPS, Cloud Computing and Data Analytics, transforming a traditional company into a Smart Factory and developing a $\mathrm{CN}$ among areas which have allowed:

- Real-time information at all levels.

- $\quad$ Production programming, supply.

- Consumption.

- Costs.

- $\quad$ Expenses (including travel expenses).

In terms of security, covering all main obstacles that lead into Industry 4.0:

- Restrictive costs, authorization is needed to request more inventory.

- Lots identified, does not allow mixing if it is not part of the process.

- Complete traceability of the pieces.

- Control of the mixtures used.

- Flexibility, security, and implementation.

- $\quad$ Real-time data management with information protected by high-performance servers and security standards. 
In the future, the company seeks full control of its activities in both nations, responding to the changing needs of customers more efficiently, minimizing any delay contemplating supplies and suppliers within the system, responsiveness and flexibility, to provide a solution to problems more accurately with the knowledge of the business; improve the cost analysis, to offer better prices in real time and differentiate from the rest of the competitors with its response capacity.

\section{Conclusion}

EOS solution has proven to be a system that allows it to be adapted into companies from different sectors creating a collaborative network that could transcend other entities, thus, it offers a gradual transition to the Industry 4.0 of its clients, connection among areas of the company.

The contributions to Industry 4.0 offered are:

Innovation. In the logistic process by incorporating all areas of the business, in the production part to be able to monitor the entire production chain and verify its status continuously. In the services offered, to include both suppliers and customers within the system giving a more precise answer to the needs processed by cognitive system with real knowledge of the environment, increasing Reconfigurability.

The technologies that the system uses are essentially sensors and CPS, as well as the IIoT and Cloud Computing to monitor information in real time from anywhere, increasing Digitalization. Not only, all the users of EOS have their information available, through different security protocols, data protection is guaranteed, but also, Flexibility for enterprises are increased due to the lack of hardware for storing information.

For the implementation of the LOVIS EOS in a company, it is required to know in detail the operation of the same, thus, locating points of information that flow and that are necessary for the optimal functioning of activities. Information Transparency ensures that the information reflected corresponds to reality, status verification points and restrictions of the physical world. Taking advantage of the IIoT to use real-time measurements of the interconnected process and Big Data to optimize resources and the cycles of them. In addition, by not being a rigid system, allows the expansion of the company, both vertically and horizontally. Thus, EOS solution is a viable option for any size of company which offers a complete transformation of how activities are carried out in an organization, either for the production of goods or the supply of services, transforming a traditional process into a more flexible, reconfigurable and intelligent one.

EOS has provided benefits when it is compared to traditional enterprise applications, implemented in more than 27 industry sectors and in less than twelve months without operational interruptions, providing a Return of Investment (ROI) of at least $100 \%$ during the first year of operations [16]. Thus, it is proven as a system that contributes to the formation of companies within Industry 4.0 creating cognitive systems from collaborative networks. 


\section{Acknowledgments}

The development of this work was carried out in conjunction with the company LOVIS and CONACyT funds, giving the corresponding authorship to both organizations.

\section{References}

1. Weichhart, G., Molina, A., Chen, D., Whitman, L. E., \& Vernadat, F. (2016). Challenges and current developments for Sensing, Smart and Sustainable Enterprise Systems. $\begin{array}{lllll}\text { Computers in } \quad \text { Industry, } & \text { 79(Supplement } & \text { C), }\end{array}$ doi:https://doi.org/10.1016/j.compind.2015.07.002

2. Herterich, M. M., Uebernickel, F., \& Brenner, W. (2015). The Impact of Cyber-physical Systems on Industrial Services in Manufacturing. Procedia CIRP, 30(Supplement C), 323328. doi:https://doi.org/10.1016/j.procir.2015.02.110

3. Camarinha-Matos, L. M. (2014). Collaborative Networks: A Mechanism for Enterprise Agility and Resilience. In K. Mertins, F. Bénaben, R. Poler, \& J.-P. Bourrières (Eds.), Enterprise Interoperability VI: Interoperability for Agility, Resilience, and Plasticity of Collaborations (pp. 3-11). Cham: Springer International Publishing.

4. Dilberoglu, U. M., Gharehpapagh, B., Yaman, U., \& Dolen, M. (2017). The Role of Additive Manufacturing in the Era of Industry 4.0. Procedia Manufacturing, 11(Supplement C), 545-554. doi:https://doi.org/10.1016/j.promfg.2017.07.148

5. Zezulka, F., Marcon, P., Vesely, I., \& Sajdl, O. (2016). Industry 4.0 - An Introduction to $\begin{array}{lll}\text { the } & \text { phenomenon. }\end{array}$ doi:https://doi.org/10.1016/j.ifacol.2016.12.002

6. Ferreira, I. A., \& Alves, J. L. (2017). Low-cost 3D food printing. Ciência \& Tecnologia dos Materiais, 29(1), e265-e269. doi:http://dx.doi.org/10.1016/j.ctmat.2016.04.007

7. Oussous, A., Benjelloun, F.-Z., Ait Lahcen, A., \& Belfkih, S. (2017). Big Data technologies: A survey. Journal of King Saud University - Computer and Information Sciences. doi:https://doi.org/10.1016/j.jksuci.2017.06.001

8. Hermann, M., Pentek, T., \& Otto, B. (2016, 5-8 Jan. 2016). Design Principles for Industrie 4.0 Scenarios. Paper presented at the 2016 49th Hawaii International Conference on System Sciences (HICSS)

9. Lucke, D., Constantinescu, C., \& Westkämper, E. (2008, 2008//). Smart Factory - A Step towards the Next Generation of Manufacturing. Paper presented at the Manufacturing Systems and Technologies for the New Frontier, London.

10. Weiser, M. (1991). The computer for the twenty-first century (pp. 94-100). Scientific American, September Issue.

11. Schröder, C. (2016). The Challenges of Industry 4.0 for Small and Medium-sized Enterprises.

12. Varghese, A., \& Tandur, D. (2015). Wireless requirements and challenges in Industry 4.0.

13. Becker, J., \& Delfmann, P. (2007). Reference modeling: Efficient information systems design through reuse of information models.

14. Chavarría-Barrientos, D., Camarinha-Matos, L. M., \& Molina, A. (2017). Achieving the Sensing, Smart, and Sustainable "Everything", Cham. Chavarria-Barrientos, D., Batres, R., Perez, R., Wright, P. K., \& Molina, A. (2016).

15. A Step Towards Customized Product Realization: Methodology for Sensing, Smart and Sustainable Enterprise, Cham. 
16. Yusuf, Y. Y., Sarhadi, M., \& Gunasekaran, A. (1999). Agile manufacturing:: The drivers, concepts, and attributes. International Journal of Production Economics, 62(1), 33-43.

17. Chavarria-Barrientos, D., Chen, D., Funes, R., Molina, A., \& Vernadat, F. (2017). An Enterprise Operating System for the Sensing, Smart, and Sustainable Enterprise. IFACPapersOnLine, 50(1), 13052-13058. doi:https://doi.org/10.1016/j.ifacol.2017.08.2004

18. Council on Systems Engineering, I. (2015). INCOSE Systems Engineering Handbook: A Guide for System Life Cycle Processes and Activities. 